\title{
Mutations in gyrA and parC Genes in Quinolone-Resistant Klebsiella pneumoniae Isolates from Borujerd Hospitals
}

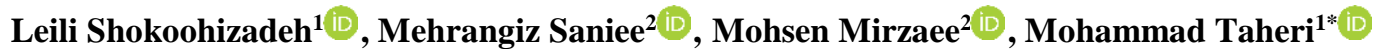 \\ 1. Dept. of Medical Microbiology, Faculty of Medicine, Hamadan University of Medical Sciences, Hamadan, Iran \\ 2. Dept. of Medical Laboratory Sciences, Borujerd Branch, Islamic Azad University, Borujerd, Iran
}

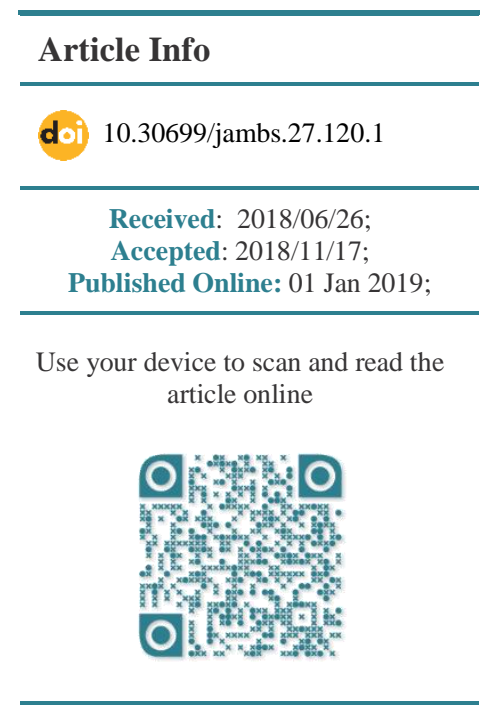

Corresponding Information: Mohammad Taheri, Dept. of Medical Microbiology, Faculty of Medicine, Hamadan University of Medical Sciences, Hamadan, Iran Email: motaheri360@gmail.com

\begin{abstract}
Background \& Objective: Quinolones are the antibiotics used to treat infections. Several reports have indicated the increased resistance to quinolone in Klebsiella pneumoniae strains all over the world. The aim of this study was to investigate amino acid substitutions in GyrA and ParC proteins among quinolone-resistant isolates of $K$. pneumoniae in Borujerd (west of Iran) hospitals.
\end{abstract}

Materials \& Methods: Totally, 100 isolates of K. pneumoniae were collected. After validating the isolates by conventional laboratory methods, an antimicrobial susceptibility test was carried out for some antibiotics from the quinolones family. Quinolone resistance and Minimum Inhibitory Concentration (MIC) of Ciprofloxacin were detected by disk diffusion and E-test methods, respectively. The amplification of gyrA and $\operatorname{parC}$ genes in quinolone-resistant strains was performed by PCR using specific primers. PCR products were sequenced in order to detect the mutations in $g y r A$ and $\operatorname{par} C$ genes.

Results: Generally, $38 \%$ of all the collected isolates were resistant to Nalidixic acid and Ciprofloxacin, $18 \%$ were resistant to Ofloxacin, and $15 \%$ were resistant to Norfloxacin. Concurrent resistance to Nalidixic acid, Ciprofloxacin, Ofloxacin, and Norfloxacin was determined in $15 \%$ of the cases. In $86 \%(\mathrm{n}=20)$ of Ciprofloxacinresistant strains, MIC was measured $128 \mu \mathrm{g} / \mathrm{mL}$. The mutation rate was $40 \%(\mathrm{n}=9)$ in gyrA gene in quinolone-resistant strains and $35 \%(\mathrm{n}=8)$ in parC gene.

Conclusion: Briefly, our research findings revealed that a relatively high resistance to quinolones as well as fluoroquinolone was observed among $K$. pneumoniae isolates in Brojurd hospitals. It is likely that mutation occurrence in certain positions of gyrA and parC genes has a significant effect on developing high-level resistance to quinolone in K. pneumoniae.

Keywords: Klebsiella pneumoniae, gyrA and parC mutations, Quinolone resistance

\section{Introduction}

Klebsiella pneumoniae is a kind of intestinal gramnegative bacterium causing a broad range of diseases, including bacteremia, pneumonia, and urinary tract infections. The importance of this opportunist bacterium has been determined in recent years. As a result of excessive consumption of antibiotics, some drug-resistant strains of this bacterium have emerged and spread (1).

Due to the overuse of antibiotics, for instance, cephalosporins, in recent years, the prevalence of infections by $K$. pneumoniae isolates producing broadspectrum beta-lactamases has been significantly reported worldwide (2). Fluoroquinolones are often used as an empirical treatment for many nosocomial and nonhospital infections resulted from multidrug-resistant gram-negative pathogens (3).

Quinolones were introduced as a Nalidixic acid for the first time in 1962. For five decades, different types of quinolones have been prescribed for clinical use $(4,5)$.
Fluoroquinolones are fluorinated quinolone derivatives such as Ciprofloxacin and Levofloxacin carrying a similar mechanism of action. These drugs were initially introduced because of their activity against aerobic gramnegative bacteria such as $K$. pneumoniae. They have a high antibacterial effect and a small amount of toxicity. They also reach appropriate therapeutic levels in tissues and blood. Due to the fact that $K$. pneumoniae is a leading cause of urinary tract infections, fluoroquinolones can be the most appropriate antibiotic for this bacterium. Ciprofloxacin is an oral or intravenous antibiotic widely used for treating urinary tract infections due to its rapid effect. Quinolone compounds cause their antibacterial activity through their inhibitory effect on certain known topoisomerase enzymes called DNA gyrase (Topoisomerase II) and Topoisomerase IV which are coded by gyrA and parC genes. Heterothermic proteins consist of two Subunits A and B of the two enzymes mentioned earlier $(6,7)$. 
Resistance to fluoroquinolones in gram-negative bacteria is often due to chromosomal mutations, the displacement of specific amino acids in the quinoloneresistant domain (QRD) of gyrA and gyrB genes (7). Also, mutations decreasing the drug accumulation and plasmids protecting the bacteria from the killing effects of quinolones have an important role in resistance to quinolones (8). At first, mutations diminish the susceptibility of the gyrase enzyme in the bacteria, then others in gyrA or parC can increase resistance to these antibiotics. A region of DNA known as "quinolone resistance-determining region" (QRDR) can affect the resistance of bacteria against these antibiotics via the amino acid substitution in this region (8).

Considering the importance of controlling $K$. pneumoniae infections in hospitals and decreasing the antibiotic resistance such as resistance to quinolones, no studies have been conducted on mutations in gyrA and parC genes in Borujerd hospitals. The present study aimed to investigate the amino acid substitutions of GyrA and ParC proteins in the clinical isolates of $K$. pneumoniae with high-level quinolone resistance in Borujerd hospitals.

\section{Materials and Methods}

\section{Klebsiella pneumoniae Isolates}

In a cross-sectional study, in total, $100 \mathrm{~K}$. pneumoniae isolates were randomly isolated from clinical samples, including wounds $(4 \%)$, blood $(3 \%)$, trachea $(15 \%)$, and urine $(78 \%)$ samples of patients hospitalized in different (ICU, pediatric, emergency, and internal) wards in three hospitals of Borujerd, in the west of Iran.

\section{Antimicrobial Susceptibility Test}

The antibiotic susceptibility of isolated $K$. pneumoniae to quinolone antibiotics, including Ciprofloxacin $(30 \mu \mathrm{g})$, Norfloxacin $(30 \mu \mathrm{g})$, Nalidixic acid $(10 \mu \mathrm{g})$, and Ofloxacin $(5 \mu \mathrm{g})$ was tested using a standard disk diffusion method. Then the determination of Ciprofloxacin MICs by E-test was carried out according to CLSI criteria. Standard strain K. pneumoniae ATCC 12022 was considered as a control.

\section{E-test Procedure}

To change the susceptibility or resistance of the isolated bacteria from Enterobacteriaceae family to Ciprofloxacin based on CLSI criteria for MIC, values of $1 \mu \mathrm{g} / \mathrm{mL}$ were considered as sensitive while the values of $2 \mu \mathrm{g} / \mathrm{mL}$ and $\geq 4 \mu \mathrm{g} / \mathrm{mL}$ were considered as semi-susceptible and resistant, respectively.

\section{DNA Extraction and PCR Assay}

PCR and sequencing were performed to amplify and detect mutations in gyrA and parC genes in quinolone and also fluoroquinolone-resistant $K$. pneumoniae isolates. Generally, the genomic DNAs of the mentioned isolates were extracted by a commercial DNA extraction kit (Cinapure DNA, CinaClon, Iran) according to the manufacturer's instructions and were amplified by PCR assay. The oligonucleotide primers used in the PCR reactions were gyrA-F (5'-CGACCTTGCGAGAGAAAT3'); gyrA-R (5'-GTTCCATCAGCCCTTCAA-3'), and primer parC-F (5'-TACGTCATCATGGACAGG-3'); parC-R (5'-GCCACTTCACGCAGGTTG-3') (Metabion, Germany). For all amplification reactions, a PCR mixture was used which contained $12.5 \mu \mathrm{L}$ of $2 \mathrm{X}$ Master Mix (Ampliqon, Denmark) in the total volume of $50 \mu \mathrm{L}$. DNA amplification was performed in a thermocycler (PEQ STAR, Germany). For gyrA, the PCR program was: an initial denaturation at $98^{\circ} \mathrm{C}$ for 5 minutes, 35 cycles of denaturation at $94^{\circ} \mathrm{C}$ for 1 minute, 1 minute of annealing at $64^{\circ} \mathrm{C}$, and 2 minutes of extension at $72^{\circ} \mathrm{C}$, and final extension at $72^{\circ} \mathrm{C}$ for 5 minutes. The temperature profile for parC gene was comprised of $95^{\circ} \mathrm{C}$ for 2 minutes, followed by 35 cycles of 1 minute at $95^{\circ} \mathrm{C}, 1 \mathrm{~min}$ of annealing at $60^{\circ} \mathrm{C}, 2$ minutes of extension at $72^{\circ} \mathrm{C}$, and final extension of 10 minutes at $72^{\circ} \mathrm{C}$. DNA fragments were analyzed by agarose gel electrophoresis ( $1 \%, \mathrm{wt} / \mathrm{vol})$ containing $0.5 \mathrm{mg}$ of ethidium bromide per liter and visualized by ultraviolet illumination.

The sequencing of PCR products was carried out using the Applied Biosystems DNA analyzers sequencing system (Bioneer Co., Korea). To detect the mutation in gyrA and parC genes, the sequences of these genes in Ciprofloxacinresistant strains were copied in FASTA format in online pairwise alignment tools (Emboss/needle), then they were aligned with the sequences of gyrA and par $\mathrm{C}$ genes of the wild-type strain of $K$. pneumoniae.

\section{Statistical Analysis}

SPSS version 21 (SPSS Inc., Chicago, IL., USA) was employed for statistical analysis. Descriptive statistics and Pearson's chi-square tests were used to evaluate the correlation between the mutation and Ciprofloxacin resistance. P-values less than 0.05 were considered as statistically significant.

\section{Results}

\section{Resistance to Fluoroquinolones}

The results demonstrated that among $100 \mathrm{~K}$. pneumoniae isolates, 38 of them were resistant to Nalidixic acid and Ciprofloxacin, simultaneously, while 18 and 15 isolates were resistant to Ofloxacin and Norfloxacin, respectively. Furthermore, 15 isolates were resistant to Nalidixic acid, Ciprofloxacin, Ofloxacin, and Norfloxacin, simultaneously. The presence of mutations in $g y r \mathrm{~A}$ and $g y r \mathrm{~B}$ genes was evaluated in 38 quinoloneresistant isolates (Figure 1). Mutations were detected in $37 \%(\mathrm{n}=14)$ of them. The frequencies of mutations in gyrA, par $\mathrm{C}$, and both gyrA and parC were $64 \%(\mathrm{n}=9)$, $57 \%(\mathrm{n}=8)$, and $21 \%(\mathrm{n}=3)$ in strains with point mutations (Figure 2). In $63 \%(n=24)$ of quinolone-resistant strains, no mutations were detected at all. According to the results of our E-test, MIC values ranged from $2 \mu \mathrm{g} / \mathrm{mL}$ to 128 $\mu \mathrm{g} / \mathrm{mL}$, whereas 20 isolates $(86 \%)$ resistant to Ciprofloxacin with $\mathrm{MIC}=128 \mu \mathrm{g} / \mathrm{mL}$ were determined. The MIC values including $64 \mu \mathrm{g} / \mathrm{mL}$ and $2 \mu \mathrm{g} / \mathrm{mL}$ were detected in one (4.5\%) and two $(8.5 \%)$ of the Ciprofloxacin-resistant isolates, respectively. 


\section{Sequencing of the parC and gyrA QRD:}

The results of sequencing data were acquired and analyzed using Chromas software. Then the nucleotide sequences were compared and the protein sequences of the mutations created in the gyrA and parC genes were evaluated. The results are presented in Table 1. Data sequences were examined to detect the presence of amino acid substitution in certain positions. Fourteen amino acid substitutions in GyrA and 16 amino acid substitutions in ParC proteins were observed in quinolone-resistant isolates. These results are presented in Table 1 and Figure 2.

In the case of GyrA protein, 14 point mutations were detected at position numbers: $\mathrm{Arg} 232 \rightarrow \mathrm{Gln}$, Val437 $\rightarrow$ Ala, His194 $\rightarrow$ Gln, Ala204 $\rightarrow$ Ser, Arg207 $\rightarrow$ Trp, Leu210 $\rightarrow$ Tyr, and Arg214 $\rightarrow$ Cys, Pro216 $\rightarrow$ Ser and Ser83, 217, 21 $\rightarrow$ Phe,
Asp232 $\rightarrow$ Ala, Arg502 $\rightarrow$ Met. Five- and two-point mutations in GyrA were detected in two isolates by number 7 and 11, respectively (Table 1). In the case of ParC protein, 16 amino acid substitutions were detected at position numbers: Trp10, $208 \rightarrow$ Arg, Trp11 $\rightarrow$ Cys, Met46 $\rightarrow$ Thr, Ser141, 143 and $80 \rightarrow$ Ile, 139 and Gln149 $\rightarrow$ His, Lys155 $\rightarrow$ Glu, Ser196 $\rightarrow$ Pro, Gly205 $\rightarrow$ Trp, Ser211 $\rightarrow$ Ala, Leu245 $\rightarrow$ Ser. Two-point mutations in ParC were detected in 4 isolates (isolates by numbers $8,11,29,61$ ) and five-point mutations were detected in one isolate (by number 90). Also, a double mutation in gyrA and parC genes was identified in 3 strains (strains number 6,8 , and 11) and most of the quinolone-resistant strains exhibited a high MIC value $(128 \mu \mathrm{g} / \mathrm{mL})$.

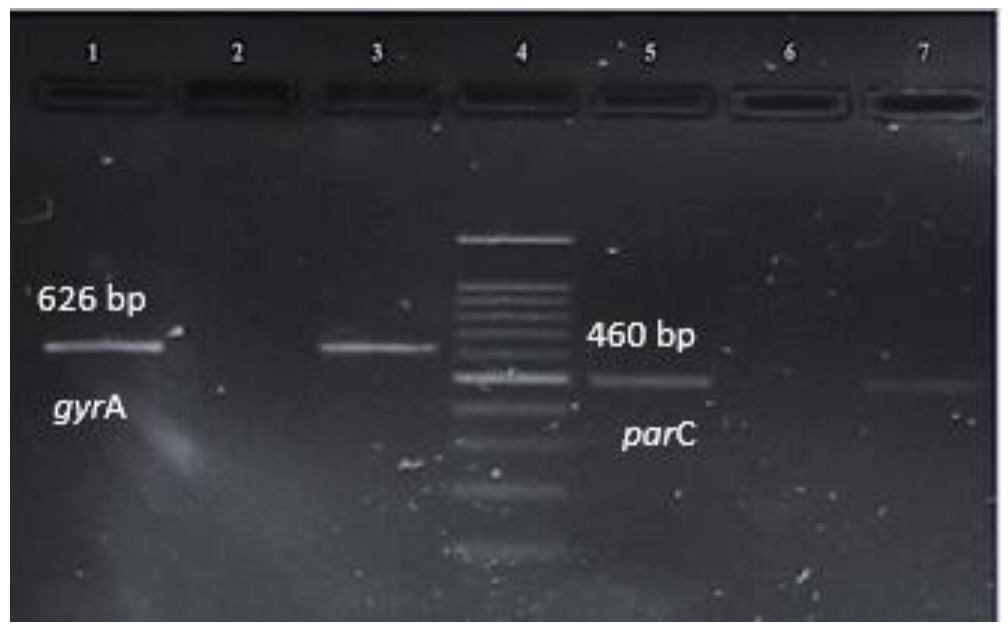

Figure 1. Gel electrophoresis of PCR products for $\operatorname{gyr} \mathrm{A}$ and $\operatorname{parC}$ genes. The $\mathbf{1}^{\text {st }}$ lane represents the positive control for $\operatorname{gyrA}$, the $2^{\text {nd }}$ lane shows the negative control, the $3^{\text {rd }}$ lane is a sample containing gyrA and lane 4 represents a 100 bp DNA size marker; the $5^{\text {th }}$ and $6^{\text {th }}$ lanes show the positive and negative controls of $\operatorname{par} C$ gene, respectively; the $7^{\text {th }}$ lane shows the parC sample.

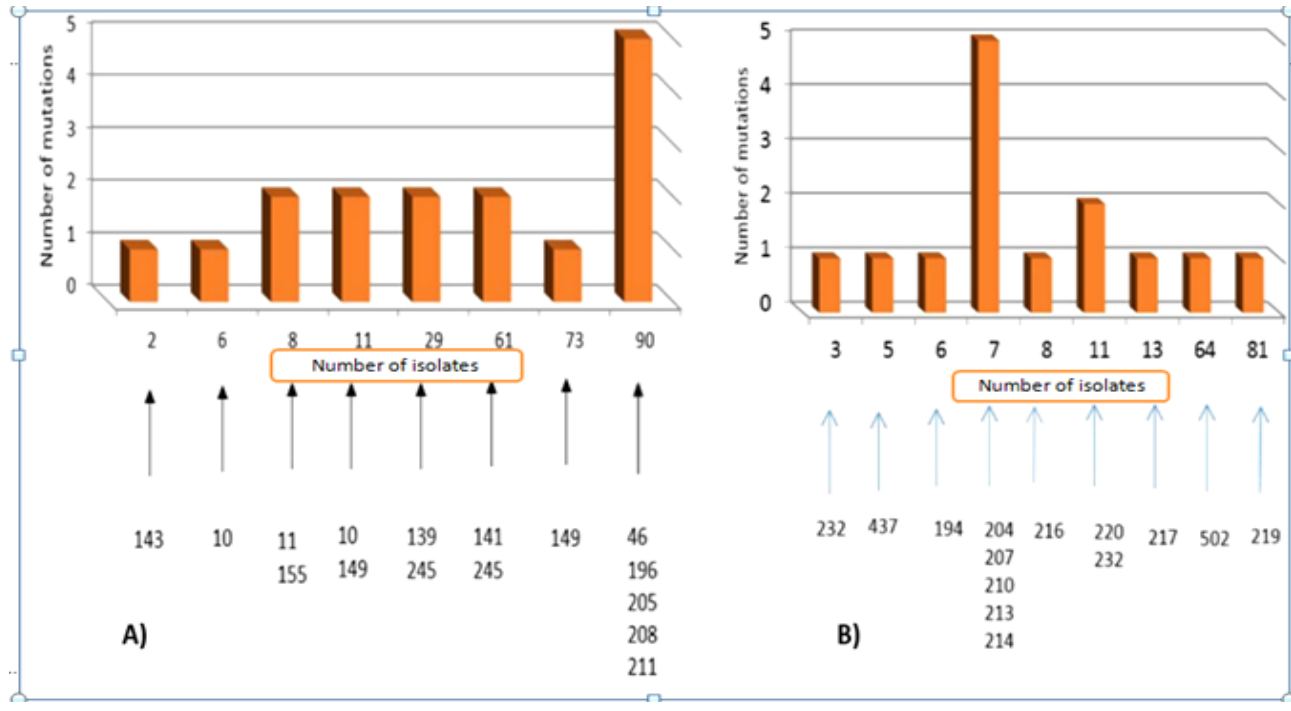

Figure 2. Substitution of amino acids and number of mutations in parC gene (A) and gyrA gene (B) in $K$. pneumoniae isolates. 
Table 1. Substitution of amino acids in GyrA and ParC proteins in K. pneumoniae isolates

\begin{tabular}{|c|c|c|c|c|}
\hline \multirow{2}{*}{ Number Strain } & \multicolumn{2}{|c|}{ Codon $\&$ Amino acid substitution } & \multirow{2}{*}{$\begin{array}{l}\text { MIC } \\
\mu \mathrm{g} / \mathrm{mL}\end{array}$} & \multirow{2}{*}{ Isolated } \\
\hline & gyrA & $\operatorname{parC}$ & & \\
\hline \multirow{2}{*}{2} & - & $\mathrm{AGC} \rightarrow \mathrm{ATC}$ & \multirow{2}{*}{128} & \multirow{2}{*}{ Urine } \\
\hline & - & Ser $80 \rightarrow$ Ile & & \\
\hline \multirow{2}{*}{3} & $\mathrm{CGA} \rightarrow \mathrm{CAA}$ & - & \multirow{2}{*}{128} & \multirow{2}{*}{ Urine } \\
\hline & Arg $232 \rightarrow$ Gln & - & & \\
\hline \multirow{2}{*}{5} & $\mathrm{GTC} \rightarrow \mathrm{GCC}$ & - & \multirow{2}{*}{2} & \multirow{2}{*}{ Urine } \\
\hline & Val437 $\rightarrow$ Ala & - & & \\
\hline \multirow{2}{*}{6} & $\mathrm{CAT} \rightarrow \mathrm{CAG}$ & $\mathrm{TGG} \rightarrow \mathrm{ACG}$ & \multirow{2}{*}{2} & \multirow{2}{*}{ Urine } \\
\hline & His $194 \rightarrow$ Gln & $\operatorname{Trp} 10 \rightarrow \operatorname{Arg}$ & & \\
\hline \multirow{10}{*}{7} & $\mathrm{GCA} \rightarrow \mathrm{TCA}$ & - & \multirow{10}{*}{128} & \multirow{10}{*}{ Trachea } \\
\hline & Ala $204 \rightarrow$ Ser & - & & \\
\hline & $\mathrm{CGG} \rightarrow \mathrm{TGG}$ & - & & \\
\hline & $\operatorname{Arg} 207 \rightarrow \operatorname{Trp}$ & - & & \\
\hline & $\mathrm{CTC} \rightarrow \mathrm{TAC}$ & - & & \\
\hline & Leu $210 \rightarrow$ Tyr & - & & \\
\hline & $\mathrm{CGC} \rightarrow \mathrm{TGC}$ & - & & \\
\hline & $\operatorname{Arg} 213 \rightarrow$ CyS & - & & \\
\hline & $\mathrm{CGC} \rightarrow \mathrm{TGC}$ & - & & \\
\hline & Arg214 $\rightarrow$ Cys & - & & \\
\hline \multirow{4}{*}{8} & $\mathrm{CCG} \rightarrow \mathrm{TCG}$ & $\mathrm{TGG} \rightarrow \mathrm{TGT}$ & & \\
\hline & Pro216 $\rightarrow$ Ser & Trp11 $\rightarrow$ Cys & 128 & Trachea \\
\hline & - & $\mathrm{AAA} \rightarrow \mathrm{GAA}$ & 128 & Iracnea \\
\hline & - & Lys $155 \rightarrow$ Glu & & \\
\hline & $\mathrm{TCC} \rightarrow \mathrm{TTC}$ & $\mathrm{TGG} \rightarrow \mathrm{GGG}$ & & \\
\hline & Ser $83 \rightarrow$ phe & Trp10 $\rightarrow$ Gly & & \\
\hline 11 & $\mathrm{GAC} \rightarrow \mathrm{GCC}$ & $\mathrm{CAG} \rightarrow \mathrm{CAT}$ & 128 & Urine \\
\hline & Asp87 $\rightarrow$ Ala & Gln149 $\rightarrow$ His & & \\
\hline 13 & $\mathrm{TCC} \rightarrow \mathrm{TTC}$ & - & & \\
\hline 13 & Ser83 $\rightarrow$ phe & - & 128 & Urine \\
\hline & - & $\mathrm{CAG} \rightarrow \mathrm{CAT}$ & & \\
\hline 29 & - & Gln139 $\rightarrow$ His & 128 & Urine \\
\hline 29 & - & $\mathrm{TTG} \rightarrow \mathrm{TCG}$ & 128 & Urine \\
\hline & - & leu245 $\rightarrow$ Ser & & \\
\hline & - & $\mathrm{AGC} \rightarrow \mathrm{ATC}$ & & \\
\hline 61 & - & Ser80 $\rightarrow$ Ile & 128 & \\
\hline 61 & - & $\mathrm{ATC} \rightarrow \mathrm{AGC}$ & 128 & Urine \\
\hline & - & $\mathrm{Ile} 245 \rightarrow \mathrm{Ser}$ & & \\
\hline 64 & $\mathrm{AGG} \rightarrow \mathrm{ATG}$ & - & 128 & Urine \\
\hline 64 & $\operatorname{Arg} 502 \rightarrow$ Met & - & 128 & Urine \\
\hline 73 & - & $\mathrm{AGC} \rightarrow \mathrm{ATG}$ & 128 & \\
\hline 73 & - & Ser80 $\rightarrow$ Ile & 128 & Urine \\
\hline 81 & $\mathrm{TCC} \rightarrow \mathrm{TTC}$ & - & 128 & Urine \\
\hline & Ser $83 \rightarrow$ Phe & - & & \\
\hline & - & $\mathrm{ATG} \rightarrow \mathrm{ACG}$ & & \\
\hline & - & Met $46 \rightarrow$ Thr & & \\
\hline & - & $\mathrm{TCC} \rightarrow \mathrm{CCC}$ & & \\
\hline & - & Ser196 $\rightarrow$ Pro & & \\
\hline 90 & - & $\mathrm{GGA} \rightarrow \mathrm{AGA}$ & & \\
\hline 90 & - & Cly205 $\rightarrow$ Trp & 64 & Urine \\
\hline & - & $\mathrm{TGG} \rightarrow \mathrm{CGG}$ & & \\
\hline & - & $\operatorname{Trp} 208 \rightarrow \operatorname{Arg}$ & & \\
\hline & - & $\mathrm{TCA} \rightarrow \mathrm{GCA}$ & & \\
\hline & - & Ser211 $\rightarrow$ A19 & & \\
\hline
\end{tabular}




\section{Discussion}

In this study, a relatively high resistance (38\%) to fluoroquinolones including Ciprofloxacin was observed among K. pneumoniae isolates in Borujurd hospitals. In general, the findings of this study indicate that mutations in certain positions of gyr A and parC genes may have a profound impact on developing a high-level resistance to quinolone in $K$. pneumoniae. However, other mechanisms of resistance to quinolones should be considered. According to the results, the frequency of point mutations in gyrA and parC genes was $37 \%$ in quinolone-resistant strains. This suggests that other mechanisms can have a role in resistance to quinolone, along with the mutations in gyrA and parC genes. Bacteria gain resistance to quinolones in several ways such as changes in target enzymes including DNA gyrase and topoisomerase IV, changes in the endocytic pathways like penetrating the antimicrobial agent, increasing efflux pumps, and decreasing porin-expressions (9-11), and obtaining Qnr plasmids $(2,3)$. In addition to the plasmid-mediated efflux systems, chromosomal multidrug efflux pumps are able to actively remove fluoroquinolones and other agents from the bacterial cell (6). It has been proved that the main mechanism for resistance (which is dependent on the chromosome) to quinolones is the mutations in the genes encoding subunits $\mathrm{A}$ and $\mathrm{B}$ in DNA gyrase and topoisomerase IV. These enzymes are the main targets of quinolones.

The permeability of cell membrane and the ability of antibiotics in penetrating into the cell are key indexes in the efficacy of antibiotics such as fluoroquinolones with intracellular targets (12). The inner and outer membranes in the cell walls of gram-negative bacteria are considered as a particular barrier. Mutations created in downregulation of these proteins could increase the MIC of fluoroquinolones (13).

The real contribution of plasmid mediated quinolone resistance to the MIC of Ciprofloxacin is not obvious in Ciprofloxacin-resistant isolates. Thus, there is not a significant difference between the MICs of Ciprofloxacinresistant isolates with or without $q n r \mathrm{~B}$ genes (6). A study showed that among the $K$. pneumoniae strains producing ESBL, resistance to Ciprofloxacin is higher. Resistant strains that have mutations in the gyr A and par $\mathrm{C}$ genes, or the plasmid $a a c\left(6^{\prime}\right)-I b$-cr gene, along with the qnr genes reveal a high resistance to Ciprofloxacin (14).

Compared to our research, some studies have reported a lower resistance to quinolones as well as mutation rates in K. pneumoniae. In 2018, Mirzaii et al. reported that 15 $(6.8 \%)$ of the $220 \mathrm{~K}$. pneumoniae isolates were resistant to at least one of the quinolones and only $1(6.7 \%)$ of the
$15 \mathrm{~K}$. pneumoniae isolates was found to carry Ser83Leu substitution in gyrA protein in Tehran (15). In a study by Alijani et al. it was revealed that the Ciprofloxacin resistance rate was lower than that of our study (16). However, Huang reported much more resistance to Ciprofloxacin (more than 60\%) and also point mutations in gyrA (more than 95\%) in China hospitals (17). Thus, based on the results, the double mutation Ser83 $\rightarrow$ Leu + Asp $87 \rightarrow$ Asn was the most prevalent type of gyrA changes in antimicrobial-resistant isolates (15-18). In 2014, Norouzi et al. reported some K. pneumoniae strains substituting Ser $83 \rightarrow$ Ile and Ser $83 \rightarrow$ Phe in gyrA gene (8). Marquz et al. reported a resistance rate (37\%) to Ciprofloxacin (similar to our study) in Malaysia's hospitals (6). However, they reported that 33 isolates had multiple mutations either in gyrA alone $(n=1)$ or in both gyr A and parC regions $(\mathrm{n}=32)$. There are some differences among reports because the pattern of antibiotic resistance is different in various regions and this resistance profile is constantly changing in time with the increasing use of antibiotics.

According to the results of our study and others in Iran and Asian countries (Malaysia, Taiwan, Japan, and Singapore), the most similar findings in amino acid substitutions Ser $83 \rightarrow$ Phe in gyrA region and ser80 $\rightarrow$ Ile in parC region were those regarding $K$. pneumoniae isolates reported from Malaysia (6).

Some researchers believe that at least 3 mutations in the gyrA gene are required to produce a high level of resistance to Ciprofloxacin (18). Fu et al. identified 7 mutation patterns without any effects on drug resistance in the isolates including the mutations outside the QRDR region and the conversion of alanine 171 to serine and valine 198 to isoleucine (19).

Generally, the present study reveals that regardless of mutation position, several types of mutations in gyrA and parC genes may result in resistant strains. In 2014, Farah al-Marzooq reported that the rise of Ciprofloxacin MICs strongly correlates with the rise in the total number of mutations in gyrA and/or parC genes (6). On the other hand, our findings are in contrast with those of $\mathrm{Fu}$. Y et al. (20) and indicate that only one mutation could cause a high rate of resistance with MIC $128 \mu \mathrm{g} / \mathrm{mL}$.

In our study, quinolone-resistant strains did not show any significant mutations on specific positions of the chromosome which suggests that other mechanisms such as plasmid resistance or alteration in the efflux pumps (21) may create quinolone resistance in these strains while chromosomal resistance is not involved. In the relation between gyrA gene mutations and fluoroquinolones 
resistance, various results have been obtained. In a study in Brazil in which gene mutations in gyr $\mathrm{A}$ and $\operatorname{par} \mathrm{C}$ genes were investigated in intestinal bacteria isolated from patients, 33\% of resistant isolates had mutations in codons 21 or 23 or both, and none of the isolates susceptible to Ciprofloxacin had gene mutation in topoisomerase (3).

In general, there are some suggestions to increase knowledge about resistance to fluoroquinolones including investigating the mechanism of resistance to quinolones especially Ciprofloxacin using molecular methods and the evaluation of resistance profile to quinolones especially in hospitals. Complete antibiotic treatment can be effective in preventing microbial resistance and in implementing care plans. These inhibitive measures can also reduce antibiotic resistance. Moreover, periodic and systematic studies on resistance patterns are necessary in order to obtain an appropriate treatment regimen for patients $(22,23)$.

\section{Conclusion}

Based on our findings, the relatively high resistance to fluoroquinolones including Ciprofloxacin is significant particularly in hospitalized patients. The same amount of fluoroquinolone resistance is vital for treating patients especially for those who are hospitalized or have a weakened immune system because they should be treated by antibiotics for a long time. Resistance to Ciprofloxacin is significant in K. pneumoniae and it is feared that it will increase. Hence, it is better to use more effective quinolone antibiotics or a drug with effects similar to Ciprofloxacin such as Levofloxacin. The concomitant mutations in the QRD regions are estimated to contribute meaningfully to high-level fluoroquinolone resistance and to the presence of different substitutions at amino acids in GyrA and ParC proteins. This suggests that different sites have noticeable roles in resistance to quinolones. However, the mutations in $g y r \mathrm{~A}$ and $g y r \mathrm{~B}$ genes, other mechanisms of resistance to quinolones, their effects on resistance, and MIC changes should be investigated. Further investigations of molecular techniques so as to fully examine the genetic pattern of resistance, the existence of precise care, monitoring programs, and serious preventive measures are recommended.

\section{Acknowledgements}

We would like to express our gratitude to all members of the microbiology laboratories of hospitals in Borujerd, Iran.

\section{Conflict of Interest}

Authors declared no conflict of interests.

\section{References}

1. Hashemi A, Fallah F, Taherpour A. Evaluation of genetic pattern and determination of oqxA gene expression levels among clinical isolates of Klebsiella pneumoniae strains. J Mazandaran Univ Med Sci. 2014; 24(119): 48-61. [Article]

2. Kim MH, Lee HJ, Park KS, Suh JT. Molecular characteristics of extended spectrum $\beta$-lactamases in Escherichia coli and Klebsiella pneumoniae and the prevalence of qnr in extended spectrum $\beta$-lactamase isolates in a tertiary care hospital in Korea. Yonsei Med J. 2010; 51(5): $768-74$. [DOI:10.3349/ymj.2010.51.5.768] [PMID] [PMCID]

3. Minarini LA, Darini ALC. Mutations in the quinolone resistance-determining regions of gyrA and parC in Enterobacteriaceae isolates from Brazil. Braz J Microbiol. 2012; 43(4): 1309-14. [DOI:10.1590/S1517$83822012000400010]$ [PMID]

4. Oliphant CM, Green GM. Quinolones: a comprehensive review. Am Fam Physician. 2002; 65(3): 455-64. [Article]

5. Jacoby GA. Mechanisms of resistance to quinolones. Clin Infect Dis. 2005; 41: S120-S6. doi:10.1086/428052 [DOI:10.1086/428052] [PMID]

6. Al-Marquz F, Yusof M, Yasim M, Tay ST. Molecular analysis of ciprofloxacin resistance mechanisms in Malaysian ESBLproducing Klebsiella pneumoniae isolates and development of mismatch amplification mutation assays (MAMA) for rapid detection of gyrA and par C mutations. Biomed Res Int. 2014; 2014: 6D1630. [DOI:10.1155/2014/601630] [PMID] [PMCID]

7. Jaktaji RP, Mohiti E. Study of mutations in the DNA gyrase gyrA gene of Escherichia coli. Iran J Pharm Res. 2010; 9(1): 43-8.

8. Norouzi A, Azizi O, Hosseini H, Shakibaie S. Amino acid substitution mutations analysis of gyrA and parC genes in clonal lineage of Klebsiella pneumoniae conferring high-level quinolone resistance. J Med Microbiol Infec Dis. 2014; 2(3): 109-17.

9. Kern W, Oethinger M, Jellen-Ritter A, Levy S. Non-target gene mutations in the development of fluoroquinolone resistance in Escherichia coli. Antimicrob. Agents Chemother. 2000; 44(4): 814-20. [DOI:10.1128/AAC.44.4.814-820.2000] [PMID] [PMCID]

10. Linde HJ, Notka F, Irtenkauf C, et al. Increase in MICs of ciprofloxacin in vivo in two closely related clinical isolates of Enterobacter cloacae. J Antimicrob Chemother. 2002; 49(4): 625-30. [DOI:10.1093/jac/49.4.625] [PMID]

11. Oethinger M, Podglajen I, Kern WV, Levy SB. Overexpression of the mara or soxsregulatory gene in clinical topoisomerase mutants of Escherichia coli. Antimicrob Agents Chemother. $\quad 1998 ; \quad$ 42(8): 2089-94. [DOI:10.1128/AAC.42.8.2089] [PMID]

12. Zhou XY, Ye XG, He LT, et al. In vitro characterization and inhibition of the interaction between ciprofloxacin and berberine against multidrug-resistant Klebsiella pneumoniae. J. Antibiot. 2016; 69(10): 741-46. [DOI:10.1038/ja.2016.15] [PMID] [PMCID]

13. Zeth K, Kozjak-Pavlovic V, Faulstich M, et al. Structure and function of the PorB porin from disseminating Neisseria gonorrhoeae. Biochem. J. 2013; 449(3): 631-42. [DOI:10.1042/BJ20121025] [PMID] 
14. Seyedpour SM, Eftekhar F. quinolone susceptibility and detection of qnr and aac (6')-ib-cr genes in community isolates of Klebsiella pneumoniae. Jundishapur J Microbiol. 2014; 7(1): e11136. [DOI:10.5812/jim.11136] [PMID] [PMCID]

15. Mirzaii M, Jamshidi S, Zamanzadeh M, et al. Determination of gyrA and parC mutations and prevalence of plasmidmediated quinolone resistance genes in Escherichia coli and Klebsiella pneumoniae isolated from patients with urinary tract infection in Iran. J Glob Antimicrob Resist. 2018; 13: 197-200. [DOI:10.1016/j.jgar.2018.04.017] [PMID]

16. Moghadasi M, Mirzaee M, Mehrabi MR. Frequency of quinolone resistance and qnrb and qnrc genes in clinical isolates of Klebsiella pneumoniae. J Med Microbiol. 2017; 5(5-6): 39-45. [Article]

17. Huang Y, Ogutu JO, Gu J, et al. Comparative analysis of quinolone resistance in clinical isolates of Klebsiella pneumoniae and Escherichia coli from Chinese children and adults. Biomed Res Int. 2015; 2015: 168292. [DOI:10.1155/2015/168292] [PMID] [PMCID]

18. Erac B, Gill A, Amyes S, Gülay Z. Mutations of gyrA in ciprofloxacin resistant Escherichia coli strains. Mikrobiyol Bul. 2003; 37(2-3): 125-30.

19. Fu Y, Zhang W, Wang H, et al. Specific patterns of gyr A mutations determine the resistance difference to ciprofloxacin and levofloxacin in Klebsiella pneumoniae and Escherichia coli. BMC Infect Dis. 2013; 13(1): 8. [DOI:10.1186/14712334-13-8] [PMID] [PMCID]

20. Fu Y, Guo L, Xu Y, et al. Alteration of GyrA amino acid required for ciprofloxacin resistance in Klebsiella pneumoniae isolates in China. Antimicrob Agents Chemother. 2008; 52(8): 2980-3. [DOI:10.1128/AAC.00151-08] [PMID] [PMCID]

21. Taheri M, Moradi M, Mortazavi S, Mansouri S, Hatam G, Nouri F. Evaluation of the $900 \mathrm{MHz}$ radiofrequency radiation effects on the antimicrobial susceptibility and growth rate of Klebsiella pneumoniae. Shiraz E Med J. 2017; 18(3). [DOI:10.17795/semj44946]

22. Amin Shahidi M, Anvarinejad M, Abbasian A, et al. Characterization of multi-drug resistant ESBL producing nonfermenter bacteria isolated from patients blood samples using phenotypic methods in Shiraz (Iran). J Birjand Univ Med Sci. 2015; 22(3): 256-65.

23. Abbas Poor S, Mardaneh J, Dehbashi S, Jasemi SS. Profile of antimicrobial susceptibility isolated microorganisms from hospitalized patients in PICU ward and detection of methicillin-resistant Staphylococcus aureus and ESBLproducing bacteria by phenotypic methods. Iran South Med J. 2014; 17(4): 647-57.

\section{How to Cite This Article:}

Shokoohizadeh L, Saniee M, Mirzaee M, Taheri M. Mutations in gyrA and parC Genes in Quinolone-Resistant Klebsiella pneumoniae Isolates from Borujerd Hospitals. J Adv Med Biomed Res. 2019; 27 (120):1-7

\section{Download citation: \\ $\underline{\text { BibTeX }} \underline{\text { RIS }}|\underline{\text { EndNote }}| \underline{\text { Medlars }}|\underline{\text { ProCite }}| \underline{\text { Reference Manager }} \mid \underline{\text { RefWorks }}$}

\section{Send citation to:}

Mendeley 2 Zotero :-iRefworks $\underline{\text { RefWorks }}$ 